\title{
Pengaruh Dukungan Sosial dan Perbandingan Sosial terhadap Kesejahteraan Subjektif Ibu Muda Pengguna Media Sosial
}

\author{
Syahra Agustiani, Gazi \\ UIN Syarif Hidayatullah Jakarta \\ gazi@,uinjkt.ac.id
}

\begin{abstract}
This research was conducted to determine the influence of social support (emotional support, instrumental support, informational support, and companionship support), social comparison (opinion and ability) and age among young mothers who use social media. A sample of 200 young mothers aged 18-37 years was taken with non-probability sampling techniques. This research used Satisfaction with Life Scale (SWLS) \& Positive Negative Affect Schedule (PANAS) to measure the subjective well-being variable. The instrument for social support was arranged based on theory of Sarafino (2011). Futhermore the instrument for social comparison was modified from the Iowa-Netherlands Comparison Orientation Scale (INCOM). The results showed there was a significant influence of social support, social comparison, and age towards subjective well-being of young mothers. The minor hypothesis test of four dimensions of social support showed only one dimension that influenced subjective well-being, which was emotional support. On social comparison, one of the two dimensions that significantly influenced subjective wellbeing was ability, whereas the other dimension which was opinion did not give significant influence toward subjective well-being.
\end{abstract}

Keywords: Subjective well-being, Social support, Social comparison, Age

\begin{abstract}
Abstrak
Penelitian ini dilakukan untuk mengetahui pengaruh dukungan sosial (dukungan emosional, dukungan instrumental, dukungan informasional dan dukungan persahabatan), perbandingan sosial (opini dan ability) dan usia terhadap kesejahteraan ibu muda pengguma media sosial. Sampel pada penelitian berjumlah $200 \mathrm{ibu}$ muda yang berusia 18-37 tahun degan teknik pengambilan data non-probability sampling. Penelitian ini menggunakan Satisfaction With Life Scale (SWLS) \& Positive Negative Affect Schedule (PANAS) untuk mengukur variabel kesejahteraan subjektif. Alat ukur untuk dukungan sosial disusun berdasarkan teori dari Sarafino (2011). Selanjutnya, alat ukur untuk perbandingan sosial memodifikasi alat ukur the Iowa-Netherlands Comparison Orientation Scale (INCOM). Hasil penelitian menunjukkan bahwa ada pengaruh yang signifikan antara dukungan sosial, perbandingan sosial, dan usia terhadap kesejahteraan subjektif ibu muda. Hasil uji hipotesis minor yang menguji pengaruhempat dimensi dukungan sosial, hanya satu dimensi yang berpengaruh terhadap kesejahteraan subjektif yaitu dimensi dukungan emosional.. Pada variabel perbandingan sosial, satu dari dua dimensi yang berpengaruh terhadap kesejahteraan subjektif yaitu dimensi ability, sedangkan dimensi lainnya yaitu opini tidak berpengaruh terhadap kesejahteraan subjektif.
\end{abstract}

Kata kunci: Kesejahteraan subjektif, Dukungan sosial, Perbandingan sosial, Usia 


\section{Pendahuluan}

Kesejahteraan subjektif diartikan sebagai penilaian atau evaluasi setiap individu tentang kehidupan. Penilaian yang dimaksud mencakup penilaian kognitif seperti kepuasan hidup dan penilaian afektif atau respon emosional terhadap kehidupan yang berkelanjutan dalam aspek emosi positif dan menyenangkan, juga dalam emosi negatif dan tidak menyenangkan (Diener, et al., 2018).Kesejahteraan subjektif pada setiap individu tentunya akan berbeda-beda dapat dilihat dari mana saja, salah satunya dalam lingkup media sosial. Menurut House (2008), individu yang menggunakan media sosial mendapatkan sumber daya emosional yang bagus dari individu lain. Hal itu disebabkan karena mereka saling memberi waktu dan atensi, berbagi mengenai perasaan, berbagi saran dan kepedulian, dan memberi dukungan sosial yang mampu mempertahankan tingkat kesejahteraan subjektif yang baik bagi individu masing-masing idividu.

Ibu muda dalam masa transisi menjadi orangtua diasosiasikan dengan parental stress, kondisi dimana timbul kesulitan seperti depresi, kesulitan interaksi antara orangtua dengan anak, dan kesulitan mengasuh sehari-hari yang berlanjut sepanjang pengalaman pengasuhan (Leigh \& Milgrom, 2008). Untuk mengatasinya, ibu muda membutuhkan dukungan sosial. Selain itu, pada era digital ini media sosial menjadi salah satu alternatif bagi ibu muda mendapatkan dukungan sosial.

McDaniel, et al. (2012) pada $157 \mathrm{ibu}$ muda dengan rata-rata usia 27 tahun yang menggunakan internet untuk media sosial. Hasilnya menunjukkan bahwa ibu muda menghabiskan waktu menggunakan internet sedikitnya 3 jam dalam sehari. Lebih lanjut penelitian tersebut menyebutkan bahwa frekuensi penggunaan internet untuk media sosial ini menimbulkan perasaan terjalin dengan keluarga dan kerabat, yang kemudian menimbulkan adanya persepsi dukungan sosial.

Namun, ternyata penelitian dari Bartholomew, et al. (2012) menunjukkan bahwa frekuensi yang tinggi dalam penggunaan media sosial dapat diasosiasikan dengan rendahnya tingkat kesejahteraan subjektif pada ibu. Selain itu, survei yang dilakukan oleh Priory Group yang bekerja sama dengan National Health Service (2017) menemukan bahwa banyak orangtua yang berpikir media sosial seperti facebook menimbulkan adanya harapan hidup keluarga yang tidak realistis dan tidak terjangkau, sehingga hal ini dapat mendorong munculnya kecemasan dan juga depresi. Lebih lanjut lagi, data yang diperoleh menunjukkan bahwa dari lima orangtua, $22 \%$ mengatakan bahwa gambar terkait keluarga bahagia yang diunggah di media sosial membuat mereka merasa tidak puas terhadap dirinya. Sedangkan $23 \%$ mengatakan bahwa hal tersebut membuat mereka merasa depresi.

Faktor lain yang dapat mempengaruhi kesejahteraan subjektif adalah perbandingan sosial. Beberapa teori menyatakan bahwa kebahagiaan dihasilkan dari perbandingan antara beberapa standar yang diterapkan oleh individu dan kondisi aktual. Jika kondisi aktual melampaui standar yang diharapkan maka akan menimbulkan kebahagiaan (Diener, 1984).

Menurut teori perbandingan sosial, suatu individu menggunakan individu yang lain sebagai standar. Jika seseorang merasa lebih baik dari orang lain, orang tersebut cenderung akan lebih merasa puas dan bahagia (Diener, 1984). Selain itu, Brickman \& Bulman (dalam Buunk \& Mussweiler, 2001) mengemukakan berdasarkan asumsi dasar Festinger bahwa pilihan perbandingan sosial biasanya berorentasi pada orang lain yang dianggap lebih baik dari dirinya (superior).

Coyne, et al. (2016) dalam studinya menemukan bahwa para ibu membuat perbandingan sosial di jejaring sosial pada umumnya melaporkan tingkat persepsi mengenai peran orangtua dan tingkat depresi yang lebih tinggi. Selain itu juga menimbulkan tingkat persepsi dukungan sosial yang lebih rendah, rasa kurang puas mengenai pengasuhan, dan persepsi mengenai kompetensi orangtua yang lebih rendah. Penelitian lain menunjukkan bahwa penggunaan media sosial facebook cenderung menghasilkan tingkat perbandingan sosial dan perasaan negatif yang lebih tinggi di samping tingkat dukungan sosial yang lebih tinggi (Jang, et al., 2016)

Perbandingan sosial pada umumnya dapat memprediksi tingkat kepuasan pengasuhan yang rendah (Coyne,et al., 2017). Namun dalam konteks media sosial, dengan peningkatan diri (selfechancement) oleh tindakan perbandingan kebawah (downward comparison), para ibu untuk sementara waktu dapat meningkatkan kepercayaan diri mereka dengan menilai kinerja pengasuhan mereka dibandingkan dengan ibu lainnya. Hal itu menimbulkan hipotesa bahwa berdasarkan pengalaman 
kognitif, perbandingan kebawah dapat diasosiasikan dengan adanya tingkat kepuasan yang lebih tinggi dalam pengasuhan. Sebaliknya, perbandingan keatas cenderung diasosiasikan dengan tingkat kepuasan pengasuhan yang lebih rendah.

Selain faktor dukungan sosial dan perbandingan sosial, usia juga turut berpengaruh terhadap kesejahteraan subjektif (Diener, 1984). Individu yang berada pada usia muda dinilai memiliki kesejahteraan subjektif yang lebih tinggi dibadingkan dengan individu yang lebih tua, dan kesejahteraan subjektif suatu individu diduga semakin menurun seiring bertambahnya usia. Namun beberapa penelitian juga mengemukakan bahwa tidak ada hubungan yang konsisten antara usia dengan kesejahteraan subjektif seseorang (Diener, 2009).

Penelitian ini ingin melihat sejauh mana faktor-faktor psikologi mempengaruhi kesejahteraan subjektif ibu muda pengguna media social. Secara spesifik, faktor psikolog yang ingin dilihat adalah perbandingan social dan dukungan social.

\section{Landasan teori}

\section{Kesejahteraan Subjektif}

Diener (1999) menjelaskan bahwa kesejahteraan subjektif merupakan evaluasi subjektif seseorang mengenai kehidupan, meliputi evaluasi kognitif seperti kepuasan hidup dan evaluasi afektif mengenai peristiwa hidup seperti emosi dan mood yang dirasakan. Diener (1999) menyebutkan kesejahteraan subjektif terdiri dari dua dimensi, yaitu dimensi kognitif dan dimensi afektif

\section{Dukungan sosial}

Dukungan sosial menurut Sarafino (2011) mengacu pada kenyamanan, kepedulian, harga diri, atau bantuan yang tersedia dari seseorang atau kelompok untuk orang lain. Sarafino (2011) mengemukakan empat dimensi dalam dukungan sosial, yaitu:

1) Dukungan emosional, mencakup ungkapan empati, kepedulian, perhatian, pandangan positif, dan dorongan kepada penerima dukungan. Dukungan ini juga memberikan rasa nyaman dan ketentraman hati karena adanya rasa saling memiliki (sense of belongingness) antara pemberi dukungan dan penerima dukungan pada masa sulit.

2) Dukungan instrumental, mencakup pemberian bantuan langsung, dapat berupa bantuan finansial atau bantuan dalam mengerjakan tugas-tugas tertentu.

3) Dukungan informasional, mencakup pemberian informasi yang bermanfaat seperti saran, petunjuk, atau umpan balik tentang apa yang perlu dilakukan penerima dukungan.

4) Dukungan persahabatan, mengacu pada ketersediaan suatu individu untuk menghabiskan waktu bersama individu lainnya yang sedang berada dalam masa sulit, sehingga memberikan perasaan keanggotaan dalam sekelompok orang yang memiliki kesamaan minat dan aktifitas sosial. Dengan begitu, individu yang menerima dukungan ini akan merasa bahwa dia memiliki teman yang senasib.

\section{Perbandingan sosial}

Berdasarkan pengertian diatas, peneliti menggunakan teori dari Festinger (1954) yang dapat disimpulkan bahwa perbandingan sosial merupakan perilaku membandingkan diri yang timbul dari dorongan akan kebutuhan mengevaluasi pendapat (opinion) dan kemampuan (ability).

Menurut Festinger (1954), perbandingan sosial sebagai keinginan untuk melakukan evaluasi diri dibagi menjadi dua tipe:

1) Opinion (pendapat) yaitu ketika individu membandingkan diri sendiri dengan orang lain dalam aspek opini atau pendapat. 
2) Ability (kemampuan) yaitu ketika individu membandingkan diri sendiri dengan orang lain dalam aspek ability atau kemampuan.

\section{Metode}

Populasi dalam penelitian ini merupakan ibu muda yang ditemui di 10 lingkungan TK di Tangerang Selatan (TK Ruhama, TK Salman, TK Muharram, TK Babussalam, TK Nurul Hasanah, TK Hanifa, TK Kencana, TK Pertiwi, TK Pelita Bangsa, dan TK Arif Mulya) dengan sampel sebanyak $200 \mathrm{ibu}$ muda berusia 18-37 tahun. Teknik pengambilan sampel yang digunakan adalah purposive sampling. Dalam penelitian ini untuk menguji signifikansi pengaruh variable bebas terhadap variabel terikat menggunakan analisis multiple linear regression dengan menggunakan software IBM SPSS Statistics 20.

Instrumen penelitian yang digunakan dalam penelitian adalah sebagai berikut. Untuk mengukur kesejahteraan subjektif maka dimodifikasi alat ukur Satisfaction with Life Scale (SWLS) dari Diener, et al. (1985) untuk mengukur evaluasi kognitif dan Positive Affect Negative Affect Schedule (PANAS) dari Watson, et al. (1988) untuk mengukur evaluasi afektif. Alat ukur ini berjumlah 20 item. Skala dukungan sosial dalam penelitian disusun dengan membuat pernyataan-pernyataan berdasarkan teori yang dikembangkan oleh Sarafino (2011) yaitu dukungan emosional, dukungan instrumental, dukungan informasional dan dukungan persahabatan. Alat ukur ini berjumlah 22 item. Skala perbandingan social memodifikasi alat ukur Gibbons \& Buunk (1999) dan disusun berdasarkan pada teori perbandingan sosial menurut Festinger (1954) yaitu perilaku yang didorong oleh keinginan individu untuk mengevaluasi diri, berdasarkan pada 2 dimensi yaitu dimensi pendapat (opinion) dan kemampuan (ability). Alat ukur ini dinamakan The Iowa-Netherlands Comparison Orientation Scale (INCOM) yang terdiri dari 11 item.

\section{Hasil dan Diskusi}

Pada tabel 1, R-Square dalam penelitian ini sebesar 0.529 atau 52.9\% $(p=0.00)$. Artinya, pengaruh variabel usia, ability, opini, dukungan persahabatan, dukungan informasional, dukungan instrumental dan dukungan emosional sebesar $52.9 \%$ sedangkan $47.1 \%$ sisanya dipengaruhi oleh variabel lain di luar penelitian ini.

Tabel 1. $R$ Square

\begin{tabular}{|c|c|c|c|c|c|c|c|c|c|}
\hline \multirow[t]{2}{*}{ Model } & \multirow[t]{2}{*}{$\mathrm{R}$} & \multirow{2}{*}{$\begin{array}{c}\mathrm{R} \\
\text { Square }\end{array}$} & \multirow{2}{*}{$\begin{array}{l}\text { Adjusted } \\
\text { R Square }\end{array}$} & \multirow{2}{*}{$\begin{array}{c}\text { Std. Error } \\
\text { of the } \\
\text { Estimate }\end{array}$} & \multicolumn{5}{|c|}{ Change Statistics } \\
\hline & & & & & $\begin{array}{c}\text { R Square } \\
\text { Change }\end{array}$ & $\begin{array}{c}\mathrm{F} \\
\text { Chang } \\
\mathrm{e}\end{array}$ & df1 & $\mathrm{df} 2$ & Sig. F Change \\
\hline 1 & $.739^{\mathrm{a}}$ & .545 & .529 & 6.86426 & .545 & 32.906 & 7 & 192 & .000 \\
\hline
\end{tabular}

Berdasarkan koefisien regresi pada tabel 1, dapat disimpulkan persamaan regresi sebagai berikut: Kesejahteraan Subjektif $=37.579+0.613$ Dukungan Emosional -0.098 Dukungan Instrumental 0.100 Dukungan Informasional + 0.085 Dukungan Persahabatan + 0.028 Opini - 0.279 Ability.

Pada tabel 2, terdapat dua koefisien regresi yang signifikan yaitu dukungan emosional dan ability 
Tabel 2. Koefisien regresi

\begin{tabular}{|c|c|c|c|c|c|}
\hline \multirow[t]{2}{*}{ Model } & \multirow{2}{*}{\multicolumn{2}{|c|}{ Unstandardized Coefficients }} & \multirow{2}{*}{$\begin{array}{c}\text { Standardized } \\
\text { Coefficients }\end{array}$} & \multirow[t]{2}{*}{$\mathrm{t}$} & \multirow[t]{2}{*}{ Sig. } \\
\hline & & & & & \\
\hline$\overline{\text { (Constant) }}$ & 37.579 & 5.280 & & 7.118 & .000 \\
\hline Dukungan emosional & .613 & .051 & .613 & 11.986 & .000 \\
\hline Dukungan instrumental & -.098 & .061 & -.098 & -1.613 & .108 \\
\hline Dukungan informasional & -.100 & .062 & -.100 & -1.604 & .110 \\
\hline Dukungan persahabatan & .085 & .062 & .085 & 1.365 & .174 \\
\hline Opini & .028 & .061 & .028 & .458 & .647 \\
\hline Ability & -.279 & .051 & -.279 & -5.444 & .000 \\
\hline Usia & -.021 & .721 & -.001 & -.029 & .977 \\
\hline
\end{tabular}

\section{Diskusi}

Kesejahteraan subjektif merupakan evaluasi subjektif seseorang mengenai kehidupan, meliputi evaluasi kognitif seperti kepuasan hidup, dan evaluasi afektif terhadap peristiwa hidup, seperti kebahagiaan dan kesedihan (Diener, 2006). Dalam penelitian ini, dari tujuh variabel independen hanya dua variabel yang memiliki pengaruh signifikan terhadap kesejahteraan subjektif, yaitu dukungan emosional dan ability.

Dukungan emosional memberikan pengaruh yang signifikan dengan nilai koefisien regresi sebesar 0.613 (Sig. 0.000) dan memberikan sumbangan terbesar dengan $\mathrm{R}^{2}$ change sebesar $45.6 \%$. Artinya, ibu muda merasakan adanya pengaruh positif dukungan emosional yang cukup tinggi terhadap kesejahteraan subjektif. Ibu muda kerap diasosiasikan dengan kondisi penurunan tingkat kesejahteraan subjektif, dan dengan adanya dukungan emosional dari teman atau keluarga, tentu memberikan rasa aman dan nyaman bagi ibu muda, Hal tersebut sejalan dengan penelitian yang dilakukan oleh Siewert (2011) yang menunjukkan bahwa dukungan emosional memiliki pengaruh terhadap kesejahteraan subjektif.

Selain itu, ability secara negatif memiliki pengaruh yang signifikan terhadap kesejahteraan subjektif, dengan nilai koefisien regresi sebesar -0.279 (Sig. 0.000). Dalam penelitian ini, ability dimaksud dengan kemampuan dalam melakukan pekerjaan tertentu. Ketika ibu muda melakukan perbandingan atas dirinya dan individu lain dalam aspek ability atau kemampuan, mereka cenderung melakukan perbandingan ke atas (upward comparison) dan membuat ibu muda merasa cemas. Meskipun dalam beberapa penelitian disebutkan bahwa perbandingan keatas membuat individu dapat melakukan self-improvement, penelitian lainnya menyebutkan bahwa perbandingan ke atas justru membuat individu merasa tertekan. Hal ini sejalan dengan penelitian yang dilakukan oleh Amaro (2019) yang menunjukkan bahwa perbandingan ke atas berpengaruh negatif terhadap kesejahteraan dan berhubungan positif dengan emosi negatif.

Dimensi lain dari dukungan sosial yaitu dukungan instrumental dalam penelitian ini tidak memberikan pengaruh secara signifikan terhadap kesejahteraan subjektif dengan koefisien regresi sebesar -0.098 (Sig. 0.108). Dukungan yang dimaksud merupakan dukungan nyata yang diperoleh individu, seperti bantuan finansial atau jasa. Pada ibu muda, dukungan instrumental kurang dirasakan dapat disebabkan karena adanya keterbatasan pada relasi baik itu keluarga, teman atau pemberi dukungan yang lain untuk memenuhi kebutuhan yang diperlukan oleh ibu muda tersebut. Hal ini sejalan dengan penelitian yang dilakukan oleh Merz, et al. (2009) yang mengatakan bahwa dukungan instrumental tidak berpengaruh secara signifikan terhadap kesejahteraan subjektif. 
Selain dukungan instrumental, dimensi dari dukungan sosial yang tidak memiliki pengaruh signifikan terhadap kesejahteraan subjektif adalah dukungan informasional. Hal ini tidak sejalan dengan penelitian yang dilakukan oleh Mendieta, et al. (2012) yang menunjukkan bahwa dukungan informasional memiliki pengaruh terhadap kesejahteraan subjektif. Hal ini mungkin disebabkan oleh kurangnya informasi yang didapatkan ibu muda, misalnya mengenai bagaimana mempertahankan kondisi kesejahteraan subjektif dalam menghadapi masa transisi menjadi seorang ibu.

Dimensi terakhir dari dukungan sosial yaitu dukungan persahabatan dalam penelitian ini juga tidak memiliki pengaruh yang signifikan terhadap kesejahteraan subjektif dengan nilai koefisien regresi sebesar 0.085 (Sig. 0.174). Hal ini tidak sejalan dengan penelitian yang dilakukan oleh Suurmeijer, et al. (2005) yang menunjukkan bahwa dukungan persahabatan adalah peran utama dari dukungan sosial, yang artinya memiliki pengaruh penting dalam kesejahteraan subjektif individu. Dalam penelitian ini, dukungan persahabatan tidak memiliki pengaruh yang signifikan dapat disebabkan karena kurangnya waktu untuk melakukan kegiatan bersama antara ibu muda dengan relasi.Selain dukungan sosial, variabel perbandingan sosial juga memiliki pengaruh yang signifikan terhadap kesejahteraan subjektif. Hal ini sejalan dengan teori yang dikemukakan Diener (1984) yang mengatakan bahwa kesejahteraan subjektif dapat dipengaruhi oleh perbandingan antara standar tertentu dan kondisi yang sebenarnya. Artinya, ketika individu merasa lebih baik dari individu yang lain, ia akan memiliki kondisi kesejahteraan yang baik. Sebaliknya, ketika individu merasa tidak lebih baik dari individu yang lain, ia cenderung akan memiliki kondisi kesejahteraan subjektif yang rendah. Teori tersebut didukung oleh penelitian yang dilakukan Emmons \& Diener (1984) yang menunjukkan bahwa perbandingan sosial merupakan prediktor yang kuat dalam kesejahteraan subjektif.

Adapun dimensi dari dukungan sosial yaitu opini dan ability. Dari dua dimensi tersebut, terdapat satu dimensi yang secara negatif memiliki pengaruh yang signifikan terhadap kesejahteraan subjektif, yaitu dimensi ability dengan nilai koefisien regresi sebesar -0.279 (Sig. 0.000). Dalam penelitian ini, ability atau kemampuan yang dimaksud adalah kemampuan dalam melakukan pekerjaan tertentu. Peneliti berasumsi bahwa ketika ibu muda melakukan perbandingan atas dirinya dan individu lain dalam aspek ability atau kemampuan, mereka cenderung melakukan perbandingan ke atas (upward comparison) dan membuat ibu muda merasa cemas. Perbandingan ke atas merupakan perbandingan yang dilakukan terhadap individu yang dianggap superior atau lebih baik. Meskipun dalam beberapa penelitian disebutkan bahwa perbandingan keatas membuat individu dapat melakukan self-improvement, penelitian lainnya menyebutkan bahwa perbandingan ke atas justru membuat individu merasa tertekan. Hal ini sejalan dengan penelitian yang dilakukan oleh Amaro (2019) yang menunjukkan bahwa perbandingan ke atas berpengaruh negatif terhadap kesejahteraan dan berhubungan positif dengan emosi negatif.

Sedangkan dimensi lain dari perbandingan sosial yaitu opini tidak memberikan pengaruh signifikan terhadap kesejahteraan subjektif dengan nilai koefisien regresi sebesar 0.028 (sig. 0.647). Dalam penelitian ini, perbandingan dalam aspek opini yang dimaksud adalah ketika individu membandingkan sudut pandang atau pendapat mengenai hal-hal tertentu dengan orang lain. Peneliti berasumsi, ibu muda cenderung jarang melakukan perbandingan dalam aspek opini dengan orang lain sehingga hal tersebut tidak mempengaruhi kesejahteraan subjektif.

Variabel lain yang digunakan yaitu usia tidak memberikan pengaruh yang signifikan terhadap kesejahteraan subjektif. Hal ini tidak sejalan dengan penelitian yang dilakukan oleh Xing \& Huang (2014) yang menunjukkan bahwa usai memiliki pengaruh terhadap kesejahteraan subjektif. Dalam penelitian ini, usia tidak memiliki pengaruh signifikan terhadap kesejahteraan subjektif dikarenakan adanya kontrol dari faktor lain yang cenderung berkorelasi dengan usia responden, seperti latar belakang pendidikan, kesehatan, pendapatan dan sebagainya. 


\section{Kesimpulan}

Berdasarkan hasil analisis data dan pengujian hipotesis, maka kesimpulan yang diperoleh dari penelitian ini adalah terdapat pengaruh yang signifikan dukungan sosial, perbandingan sosial, dan usia terhadap kesejahteraan subjektif ibu muda.

Jika dilihat berdasarkan signifikansi koefisien regresi dari masing-masing variabel independenyang telah diuji, terdapat dua dimensi yang secara signifikan mempengaruhi kesejahteraan subjektif ibu muda yaitu dukungan emosional dan ability. Sedangkan dukungan informasional, dukungan instrumental,dukungan persahabatan, opini dan usia tidak berpengaruh secara signifikan terhadap kesejahteraan subjektif ibu muda.

\section{Referensi}

Amaro, L. M., Joseph, N. T. \&, Santos, T. M. (2019). Relationship of Online Social Comparison and Parenting Satisfaction Among New Mothers: The Mediating Roles of Belonging and Emotion. Journal of Family Communication, 19 (2), 144-156.

Balaji, A. B., Claussen, A. H., Smith, D. C., Visser, S. N., Morales, M. J., \& Perou, R. (2007). Social Support Networks and Maternal Mental Health and Well-Being. Journal ofWomen's Health, 16, 10.

Barkin, J. L., Bloch, J. R., Hawkins, K. C., \& Thomas, T. S. (2014). Barriers to Optimal Social Support in the Postpartum Period. Journal of Obstetric, Gynecologic \& Neonatal Nursing, 43(4), 445-454.

Bartholomew, M. K., Sullivan, S. J. S., Glassman, M., Dush, C. M. K., \& Sullivan, J. M. (2012). New Parents' Facebook Use at the Transition to Parenthood. Interdisciplinary Journal of Applied Family Studies, 61(3), 455-469.

Bbc.com (2017). Instagram "worst for young mental health". Diakses pada tanggal 20 Oktober 2018 dari https://www.bbc.com/news/health-39955295.

Bian, Y., Hao, M., \& Li, Y. (2017). Social Networks and Subjective Well-Being: A Comparison of Australia, Britain, and China. Journal of Happiness Studies, 19(8), 2489-2508.

Buunk, B. P., \& Mussweiler, T. (2001). New Directions in Social Comparison Research. European Journal of Social Psychology, 31, 467-475.

Chiu, C. M., Huang, H. Y., Cheng, H. L., \& Chen, C. F. (2013). Exploring individuals' subjective well-being and loyalty towards social network sites from the perspective of network externalities: The Facebook case. International Journal of Information Management, 33 (3), 539-552.

Cobb, S. (1976). Social Support as a Moderator of Life Stress. Psychosomatic Medicine. 38 (5), 300-314.

Corcoran, K., Crusius, J., \& Mussweiler, T. (2011). Social Comparison: Motives, Standards, and Mechanisms. In D. Chadee (Ed.). Theories in Social Psychology, 9 (4), 119-139. 
Coyne, S. M., McDaniel, B. T., \& Stockdale, L. A. (2017). “Do you dare to compare?” Associations between maternal social comparisons on social networking sites and parenting, mental health, and romantic relationship outcomes. Computers inHuman Behavior, 70, 335-340.

Cronin, C. (2003). First-time Mothers: Identifying Their Needs, Perceptions and Experiences. Journal of Clinical Nursing, 12, 260-267.

Diener, E. \& Seligman, M. (2002). Very Happy People. Psychological Science. 13, 81.

Diener, E. (1984). Subjective Well-Being. Psychological Bulletin,95 (3), 542 - 575.

Diener, E. (2006). Guidelines for National Indicators of Subjective Well-Being. Journal of Happiness Studies, 7, 397-404

Diener, E., Emmons, R. A., Larsen, R. J., \& Griffin, S. (1985). The Satisfaction with Life Scale. Journal of Personality Assessment, 49(1), 71-75.

Diener, E., Lucas, R. E., \& Oishi, S. (2005). Subjective Well-Being: The Science of Happiness and Life Satisfaction. In C. R. Snyder, \& S. J. Lopez (Eds.), Handbook of Positive Psychology (2nd ed., pp. 63-73).

Diener, E., Oishi, S., \& Tay, L. (2018). Advances in Subjective Well-Being Research. Nature Human Behaviour, 2, 253-260.

Diener, E., Scollon, C. N., Lucas, R. E. (2009). The Evolving Concept of Subjective Well-Being: The Multifaceted Nature of Happiness. Advances in Cell Aging and Gerontology, 15, 187219.

Diener, E., Suh, E. M., Lucas, R. E., \& Smith, H. L. (1999). Subjective well-being: Three decades of progress. Psychological Bulletin, 125(2), 276-302.

Diener, R. B., \& Diener, E. (2006). The Subjective Well-Being of The Homeless, and Lessons for Happiness. Social Indicators Research,76, 185-205.

Dunkel-Schetter, C., Folkman, S., \& Lazarus, R. S. (1987). Correlates of social support receipt. Journal of Personality and Social Psychology, 53(1), 71-80.

Ec.europa.eu (2019). Young and older mothers in the EU. Diakses pada tanggal 19 Desember 2019 dari https://ec.europa.eu/eurostat/web/products- eurostat-news/-/DDN-20190801-1.

Eddington, N., \& Shuman, R. (2005). Subjective Well-Being (Happiness). Continuing Psychology Education. Diunduh pada 13 November 2018 dari http://www.texcpe.com/cpe/PDF/cahappiness.pdf.

Emmons, R. A., \& Diener, E. (1984). Factors Predicting Satisfaction Judgements: A Comparative Examination. Social Indicators Research, (16) 2, 157-167.

Emmons, R. A., \& Diener, E. (1985). Personality Correlates of Subjective Well-Being. Personality and Social Psychology Bulletin, 11(1), 89-97.

Festinger, L. (1954). A Theory of Social Comparison Processes. 
Gibbons, F. X. \& Buunk, B. P. (1999). Individual Differences in Social Comparison: Development of a Scale of Social Comparison Orientation. Journal of Personality and Social Psycholog,(76) 1. 129-142.

Glenn, N. D., \& Weaver, C. N. (1979). A Note on Family Situation and Global Happiness. Social Forces, 57(3), 960-967.

Gottlieb, B. H. (1983). Social support as a focus for integrative research in psychology. American Psychologist, 38(3), 278-287.

Hunt, M. G., Marx, R., Lipson, C., \& Young, J. (2018). No More FOMO: Limiting Social Media Decreases Loneliness and Depression. Journal of Social and Clinical Psychology, 37 (10), 751-768.

Jang, K., Park, N., \& Song, H. (2016). Social comparison on Facebook: Its antecedents and psychological outcomes. Computers in Human Behavior, 62, 147-154.

Kiecolt-Glaser, J. K., \& Newton, T. L. (2001). Marriage and health: His and hers. Psychological Bulletin, 127 (4), 472-503.

Kim, J., Ahn, J., \& Vitak, J. (2015). Korean mothers' KakaoStory use and its relationship to psychological well-being. First Monday, 20, 3-2.

Krasnova, H., Widjaja, T., Buxman, P., Wenninger, H., Benbasat, I. (2015). Why Following Friends Can Hurt You: An Exploratory Investigation of the Effects of Envy on Social Networking Sites among College-Age Users. Information Systems Research,26, 585-605.

Kross, E., Verduyn, P., Demiralp, E., Park, J., Lee, D. S., et al. (2013). Facebook Use Predicts Declines in Subjective Well-Being in Young Adults. PLoS ONE, 8(8), 1-6.

Leigh, B. \& Milgrom, J. (2008). Risk factors for antenatal depression, postnatal depression and parenting stress. BMC Psychiatry, 8 (1), 1-11.

Li, F., Bai, X., \& Wang, Y. (2013). The Scale of Positive and Negative Experience (SPANE): Psychometric Properties and Normative Data in a Large Chinese Sample. PLOS One. 8 (4), $1-9$.

Lyubomirsky, S., King, L., \& Diener, E. (2005). The benefits of frequent positive affect: Does happiness lead to success? Psychological Bulletin, 131, 803-855.

McDaniel, B. T., Coyne, S. M., \& Holmes, E. K. (2012). New mothers and media use: Associations between blogging, social networking, and maternal well-being. Maternal and Child Health Journal, 16, 1509-1517.

Mendieta, I.H.,Martin, M.A.G.,Jacinto, L.G. (2012). The Relationship Between Social Support, Loneliness, and Subjective Well Being in a Spanish sample From a Multidimensional Perspective. Springer Science+ Business Media Dordrecht,114(3),1013-1034. 
Merz, E. M., \& Huxhold, O. (2010). Wellbeing depends on social relationship characteristics: comparing different types and providers of support to older adults. Ageing and Society, 30(05), 843-857.

Negron, R., Martin, A., Almog, M., Balbierz, A., \& Howell, E. A. (2012). Social Support During the Postpartum Period: Mothers' Views on Needs, Expectations, and Mobilization of Support. Maternal and Child Health Journal, 17(4), 616-623.

Nyagah, V. W., Stephen, A., Mwania, J. M. (2015). Social Networking Sites and Their Influence on the Self-Esteem of Adolescents in Embu County, Kenya. Journal of Educational Policy and Enterpreneurial Research. 2 (1), pp 87-92/

O’Brien, K. S., Caputi, P., Minto, R., Peoples, G., Hooper, C., Kell, S., \& Sawley,

E. (2009). Upward and downward physical appearance comparisons: Development of scales and examination of predictive qualities. Body Image, 6(3), 201-206.

Parasuraman, S., Greenhaus, J. H., Granrose, C. S. (1992). Role Stressors, Social Support, and Well-Being Among Two-Career Couples. Journal of OrganizationalBehavior, 13,339-356.

Priorygroup.com (2017) How social media is fuelling anxiety and depression among parents, according to Priory expert. Diakses pada tanggal 20 Oktober 2018 dari https://www.priorygroup.com/media-centre/how-social-media-is-fuelling -anxiety-anddepression-among-parents

Sarafino, E. P. \& Smith, T. W. (2011). Health Psychology: Biopsychological Interactions.John Wiley \& Sons, Inc.

Sarason, I.G., Levine, H.M., Basham, R.B., et al. (1983). Assessing social support: The Social Support Questionnaire. Journal of Personality and Social Psychology, 44, 127-139.

Schetter, C. D., Folkman, S., Lazarus, R. S. (1987). Correlates of Social Support Receipt. Journal of Personality and Social Psychology, 53 (1), 71-80.

Schwarzer, R., \& Leppin, A. (2014). Social Support and Health: A Theoritical and Empirical Overview. Journal of Social and Personal Relationship, 8., 99-127.

Schwarzer, R., Knoll, N., \& Rieckmann, N. (2003). Social Support. Introduction to Health Psychology. Diunduh pada tanggal 28 November 2018 dari http://userpage.fuberlin.de/ health/support/schwarzer_knoll_rieckmann2004.pdf.

Strowman, S. R. (1996). The relation between media exposure and body satisfaction: An examination of moderating variables derived from social comparison theory. Doctoral Dissertations, University of New Hampshire.

Sullivan, S. J. S., Yavorsky, J. E., Bartholemew, M. K., Sullivan, J. M., Lee, M. A., Dush, C. M. K., \& Glassman, M. (2016). Doing Gender Online: New Mothers' Psychological Characteristics, Facebook Use, and Depressive Symptoms. Springer Science+Business Media, 76(5), 276289. 
Suurmeijer, T. P. B. M., Van Sonderen, F. L. P., Krol, B., Doeglas, D. M., Van Den Heuvel, W. J. A., \& Sanderman, R. (2005). The relationship between personality, supportive transactions and support satisfaction, and mental health of patiens with early rheumatoid athritis: Result from the Dutch part of the Euridiss study. Social Indicators Research, 73 (2), 179.

Time.com (2017). Why Instagram is the Worst social media for Mental Health. Diakses pada tanggal 28 Oktober 2018 dari https://time.com/4793331/instagram-social-media-mentalhealth/.

Veenhoven, R (2011). Greater happiness for a greater number: is that possible? if so, how?. Published in: Sheldon, K.M., Kashdan, T.B. \& Steger, M.F.(Eds.) Designing Positive Psychology: Taking Stock and Moving Forward. New York: Oxford University Press.

Van Lange, P. A. M. (2012). What We Should Expect from Theories in Social Psychology. Personality and Social Psychology Review, 17(1), 40-55.

Watson, D., Clark, L. A., \& Tellegen, A. (1988). Development and validation of brief measures of positive and negative affect: the PANAS scales. Journal of personality and social psychology, 54(6), 1063.

Wills, T. A. (1981). Downward Comparison Principles in Social Psychology. Psychological Bulletin, 90(2), 245-271.

Wood, J. V. (1989). Theory and Research Concerning Social Comparisons of Personal Attributes. Psychological Bulletin, 106(2), 231-248.

Wood, J. V. (1996). What is social comparison and how should we study it? Personality and Social Psychology Bulletin, 22(5), 520-537.

Xing, Z., \& Huang, L. (2014). The relationship between age and subjective well-being: Evidence from five capital cities in Mainland China. Social Indicators Research, 117, 743-756. 